\title{
Prediction of speaking fundamental frequency using the voice and speech range profiles in normal adults*
}

\author{
Seung Jin Lee ${ }^{1, * *} \cdot$ Jaeock Kim ${ }^{2}$ \\ ${ }^{I}$ Department of Otorhinolaryngology, Yonsei University College of Medicine; The Institute of Logopedics \& Phoniatrics, \\ Department of Otorhinolaryngology, Gangnam Severance Hospital, Seoul, Korea \\ ${ }^{2}$ Major in Speech Pathology Education, Graduate School of Education, Kangnam University, Yongin, Korea
}

\begin{abstract}
This study sought to investigate whether mean speaking fundamental frequency (SFF) can be predicted by parameters of voice and speech range profile (VRP and SRP) in Korean normal adults. Moreover, it explored whether gender differences exist in the absolute differences between the SFF and estimated SFF (ESFF) predicted by the VRP and SRP. A total of 85 native Korean speakers with normal voice participated in the study. Each participant was asked to perform the VRP task using the vowel /a/ and the SRP task using the first sentence of a Korean standard passage "Ga-eul". In addition, the SFF was measured with electroglottography during a passage reading task. Predictive factors of the SFF were explored and the absolute difference between the SFF and the ESFF (DSFF) was compared between gender groups. Results indicated that predictive factors were age, gender, minimum pitch and pitch range for the VRP (adjusted $R^{2}=.931$ ), and pitch range (in semi-tones) and maximum pitch for the SRP (adjusted $R^{2}=.963$ ), respectively. The SFF and ESFF predicted by the VRP and SRP showed a strong positive correlation. The DSFF of the VRP and SRP, as well as their sum did not differ by gender. In conclusion, the SFF during a passage reading task could be successfully predicted by the parameters of the VRP and SRP tasks. In further studies, clinical implications need to be explored in patients who may exhibit deviations in SFF.
\end{abstract}

Keywords: voice range profile, speech range profile, speaking fundamental frequency, VRP, SRP

\section{1. 서론}

음성 범위 프로파일(voice range profile, 이하 VRP) 혹은 포네 토그램(phonetogram)은 발성기능의 음도(pitch)와 크기(loudness) 의 측면을 평가하기 위한 검사이며, 전체 기본주파수(funda- mental frequency, 단위 $\mathrm{Hz}$ )에 따른 진폭(amplitude, 단위 $\mathrm{dB}$ )의 범 위를 반음(semitone) 단위의 이차원 프로파일 혹은 플롯으로 나 타낸 그림을 일컫기도 한다(KayPentax, 2009; Ma \& Yiu, 2011). 정상인의 경우 $\mathrm{VRP}$ 는 대개 최소 주파수대 근처에 최소 진폭 지점이 위치하고, 최대 주파수대 근처에 최대 진폭 지점이 위

\footnotetext{
* This work was supported by the Ministry of Education of the Republic of Korea and the National Research Foundation of Korea (NRF-2018S1A5A2A03032902).

** slplee80@gmail.com, Corresponding author

Received 31 July 2019; Revised 21 August 2019; Accepted 23 August 2019

(c) Copyright 2019 Korean Society of Speech Sciences. This is an Open-Access article distributed under the terms of the Creative Commons Attribution NonCommercial License (http://creativecommons.org/licenses/by-nc/4.0) which permits unrestricted non-commercial use, distribution, and reproduction in any medium, provided the original work is properly cited.
} 
치하여 우상향으로 기울어진 타원 형태가 된다. 대부분 참고 (reference)가 되는 음 자극(tone stimulus)을 듣고 대상자가 해당 음을 다양한 음량으로 산출하여 이를 플롯으로 만들어 보여주 는 방식으로 이루어진다. 아울러 주파수와 진폭의 최대 범위를 보여주는 최대 수행력 과제(maximum performance task)의 형태 로 이루어지는 경우가 많으며, 이를 통해 다양한 직군의 환자군 을 진단하고 중재의 전후 비교에 활용되어 왔다(Sataloff, 2005). 다만 전체 음도 범위에서 최대 및 최소 음량 범위를 측정하는 전체 프로토콜을 시행하는 데에는 많은 시간이 소요되므로, 축 약된 버전의 검사 프로토콜이 개발되기도 하였다(Jung, 2018). 이는 VRP의 다양한 변용을 통해 임상에서의 활용도 제고 방법 을 탐색해볼 가능성을 보여준 좋은 사례라 할 수 있다.

음성 범위 프로파일의 측정에는 다양한 프로그램이 이용될 수 있으며, 대표적인 프로그램으로는 Computerized Speech Lab(Model 4150B; KayPENTAX, Lincoln Park, NJ, USA; 이하 CSL)의 하위 모듈 프로그램인 Voice Range Profile(Model 4326; KayPENTAX, Lincoln Park, NJ, USA)이 임상에서 흔히 이용된다. VRP는 CSL 의 하드웨어를 통해 규격화된 환경에서 음역대의 측정을 가능 하게 해주고, 물리 버튼을 통해 쉽게 입력 수준(level)을 일정하 게 교정(calibration)할 수 있다. 또한 특정 음도에 해당하는 음성 입력만 받아들여 포네토그램 상에 표시해주는 음도 타겟 모드 (pitch-target mode)를 적용하여 특정 목표 음도의 입력(input)만을 기록하는 가운데 음량을 증감시키며 음량 범위를 정밀하게 측 정할 수 있는 장점도 있다(KayPentax, 2009). 그럼에도 불구하고 아직까지 연구마다 다소 상이한 프로토콜을 사용하여 통일된 프로토콜을 찾아보기 어렵다는 한계도 있다.

음성 범위 프로파일을 시행할 때에는 통상적으로 모음, 그중 에서도 $/ \mathrm{a} /$ 가 흔히 이용된다. 그러나 몇몇 선행연구들에서는 단 순히 모음을 산출하여 음도를 변화시켜 음역대를 측정하는 것 이 아니라, 다양한 발화 산출 과제를 통해 실제 대화 시 다양한 억양을 가진 발화를 산출할 때 측정되는 음역대, 즉 말소리 범 위 프로파일(speech range profile, 이하 SRP)을 확인하고자 하였 다(D'Alatri \& Marchese, 2014). 예컨대, Berg et al.(2017)은 가장 작 은 목소리, 대화 시의 목소리, 교실에서 낼 정도의 목소리, 외치 는 목소리의 네 가지 수준으로 말할 때의 SRP를 측정하여 살펴 보았는데, 수준에 따라 남성은 111.8-130.2 Hz, 여성은 161.3$246.2 \mathrm{~Hz}$ 의 범위로 나타나 여성의 경우 통상적으로 문헌에서 보고되던 것에 비해 6-7반음 정도가 낮은 것으로 나타났다. 또 한 남성은 연령이 증가함에 따라 평균 발화기본주파수(mean speaking fundamental frequency, 이하 SFF)가 증가했으며, 현재 흡 연자는 금연자나 비흡연자에 비해 최저 주파수가 더 낮았고, $\mathrm{SFF}$ 의 범위는 사회경제적 지위(socioeconomic status)와도 비례 한다고 하였다. 이러한 요인들은 발화의 음역대에 대한 연구에 서 반드시 고려하여 잘 통제해야할 변인들의 좋은 예라 하겠다.

한편 Ma et al.(2007)은 90 명의 환자와 35 명의 대조군에서 VRP 와 SRP를 통해 측정한 변수들을 이용하여 음성장애 유무를 예 측할 수 있는지에 대해 연구하였다. 그 결과, $\mathrm{VRP}$ 의 면적, 최대 강도, 최소 강도를 이용하여 $96.1 \%$ 의 정확도로 예측이 가능하
였고, SRP의 F0 범위, 최대 강도를 이용하여 $95.6 \%$ 의 정확도로 예측이 가능하다고 하였다. 이는 VRP와 SRP의 다양한 측정변 수들이 단순히 발화의 특성을 대표하는 것을 넘어서서 음성질 환의 유무에 대한 선별도구로서의 가능성을 제시한 결과라 여 겨진다. 다만 이 연구에서는 강도와 관련된 변수들이 다수 포함 되었는데, 음도와 관련된 변수들에 한정하여 이와 유사한 임상 적 유용성을 가진 결과를 이끌어낼 수 있다면 특히 음도에 이상 을 보일 수 있는 라인케 부종(Reinke's edema), 가성대 발성장애, 성대구증(sulcus vocalis), 기능적 실성증(functional aphonia), 변성 기 발성장애(mutational falsetto) 등의 다양한 음성질환에서의 활 용을 기대할 수 있다.

대화 시 발화의 음역대 특성을 가장 잘 나타낼 수 있는 대표 값 중의 하나는 $\mathrm{SFF}$ 이며, $\mathrm{SFF}$ 는 다양한 말 산출 과제를 통해 측 정할 수 있다(Ma \& Lam, 2015). SFF는 다양한 방식으로 측정이 가능한데, 그중 전기성문파형검사(EGG)를 통해 측정하는 방법 은 비침습적이면서도 발화 혹은 문단 읽기 등의 말 과제에서의 $\mathrm{SFF}$ 를 잘 반영할 수 있는 방법 가운데 하나로 알려져 있다(Kim, 2010). 그러나 모든 임상 환경에서 별도의 EGG 기기를 갖출 수 있는 것은 아니며, 경우에 따라서는 EGG 신호가 진폭, 소음 등 의 요인으로 인해 손상될 가능성이 있고(Herbst \& Dunn, 2019), 음성장애의 중증도가 심하거나 성대 접촉(glottal contact)이 크게 손상되어 $\mathrm{EGG}$ 신호가 탐지되지 않아 분석이 어렵거나, 갑상선 종(goiter)과 같은 경부의 종물(neck mass)로 인하여 EGG 전극 (electrode)의 표면을 후두의 적절한 위치에 안정적으로 부착할 수 없어 $\mathrm{EGG}$ 측정 자체가 어려운 임상 사례들도 흔히 발견된다. 이러한 경우 $\mathrm{SFF}$ 를 신뢰성 있게 측정하거나 적어도 추정할 수 있는 방법이 필요하다고 할 수 있다. 만약 정상인에서 VRP나 $\mathrm{SRP}$ 를 통해 $\mathrm{SFF}$ 를 추정할 수 있는 공식이 확립된다면, 이를 추 후 환자군에 적용하여 실제 환자가 산출하고 있는 $\mathrm{SFF}$ 와 추정 된 바람직한 $\mathrm{SFF}$ 의 차이를 근거로 중재의 방향을 설정하는 데 큰 도움을 얻을 수 있을 것으로 여겨진다.

따라서, 본 연구에서는 한국인 정상 성인에서 성별, 연령과 같은 인구학적 변수와 함께 $\mathrm{VRP}$ 및 $\mathrm{SRP}$ 의 측정 변수들을 이용 하여 문단 읽기 시 $\mathrm{EGG}$ 를 통해 측정한 평균 $\mathrm{SFF}$ 를 예측할 수 있 는지 알아보고자 하였다. 또한 추정된 발화 기본주파수(estimated $\mathrm{SFF}$, 이하 $\mathrm{ESFF}$ )와 실제 $\mathrm{SFF}$ 간 차이(differences in $\mathrm{SFF}$, 이하 $\mathrm{DSFF}$ )에 있어 성별 차이가 있는지 알아보고자 하였다.

\section{2. 연구방법}

\section{1. 연구 대상}

G*Power(Faul et al., 2009)를 통해 6개의 예측 변수로 다중회귀 분석(multiple linear regression)을 위한 최소 표본 수를 산정한 결 과, 총 77명이었다(effect size $f^{2}=0.3$, Power=0.95). 이에 연구대상 은 서울 및 경기 지역에 거주 중이며, 정상 음성을 가진 한국어 모국어 화자 85 명(남 30 명, 여 55명)으로 하였다. 평균 연령은 남 성 $32.83 \pm 12.64$ 세, 여성 $38.22 \pm 10.40$ 세로 성별 집단 간 유의한 차 이는 없었다 $(t=-1.995, p=.051)$. 직업적 음성 사용자의 비율은 남 
성 $45.45 \%$, 여성 $33.33 \%$ 로 집단 간 유의한 차이가 없었다 $(p=.479)$

대상자 가운데 흡연력이 있거나, 검사일을 기준으로 3 개월간 상기도 감염 증상이나 음성 문제를 주소로 의료기관에 내원한 이력이 있거나, 임상가나 대상자 본인의 주관적 평가에서 이상 치가 관찰된 경우 제외하였다. 보다 구체적으로는 '가을' 문단 (Kim, 2012) 읽기 시 1급 언어재활사 2인이 GRBAS(Hirano, 1981) 를 이용한 청지각 평가를 합치에 이르도록 시행하여 Grade 척도 에서 0 이 아닌 자는 제외하였다. 또한 절단점이 구축되어 있는 음성 및 참여 프로파일-한국판(Korean version of the Voice Activity and Participation Profile, 이하 K-VAPP)을 시행하여 총점이 14.5 점 이상인 자는 제외하였다(Lee et al., 2016). K-VAPP 총점은 남 성이 $3.73 \pm 4.32$ 점, 여성이 $1.96 \pm 3.42$ 점으로 성별 집단 간 유의한 차이는 없었다 $(t=1.726, p=.088)$.

\section{2. 연구 절차}

$\mathrm{VRP}$ 과제는 최대 수행력 과제의 특성 상 이후에 산출하는 음성의 질에 영향을 줄 가능성이 있었으므로, 각 대상자로 하 여금 문단 읽기 과제, SRP 과제, VRP 과제를 순서대로 수행하 도록 하였다. 녹음에는 Computerized Speech Lab(Model 4150B; KayPENTAX, Lincoln Park, NJ, USA; 이하 CSL) 하드웨어와 Real-time EGG(Model 6103; KayPENTAX, Lincoln Park, NJ, USA) 하드웨어, 단일지향성 다이나믹 마이크(SM48; SHURE, Niles, $\mathrm{IL}, \mathrm{USA}$ )를 이용하였으며, T자형 마이크 스탠드를 이용하여 마 이크를 안정적으로 거치하였다. 소프트웨어로는 문단 읽기 시 에는 CSL의 메인 프로그램을 이용하되, 채널 1 에는 음향학적 신호가, 채널 2에는 EGG 신호가 입력되도록 하였다(Lee et al., 2018). Real-time EGG의 프로그램 대신 CSL 메인 프로그램을 이 용하여 녹음한 이유는 Real-time EGG의 녹음 제한 시간(1분) 안 에 ‘가을' 문단을 모두 읽기 어렵기 때문이었다. VRP와 SRP에 는 VRP 프로그램을 이용하였다.

먼저 문단 읽기 과제에서는 전체 문단을 읽어 $\mathrm{EGG}$ 를 이용하 여 평균 $\mathrm{SFF}(\mathrm{Hz})$ 를 측정하였다. 이때 평상 시 가족 또는 친구와 대화를 하는 것처럼 자연스러운 음도와 크기로 읽도록 독려하 였다(Lee et al., 2017). SRP 과제에서는 VRP 프로그램에서 녹음 버튼을 누른 후 ‘가을' 문단의 첫 번째 문장('우리나라의 가을은 참으로 아름답다')을 읽도록 하여 VRP 플롯을 저장하였다. 한 편 VRP 과제는 선행 연구의 절차를 참고하여 /a/ 발성으로 전체 음역대를 측정하였다(Lee et al., 2018).

$\mathrm{VRP}$ 과제의 보다 구체적인 절차는 다음과 같다.

첫 번째, $\mathrm{VRP}$ 프로그램 상에서 $\mathrm{EGG}$ 의 $\mathrm{SFF}\left(\mathrm{SFF}_{\mathrm{EGG}}\right)$ 와 가급적 가까운 기본주파수의 건반을 클릭하여 해당 음도를 들려주고, 대상자가 모음 $/ \mathrm{a} /$ 로 모방하여 편안한 음도로 산출하도록 하면 서 VRP 상에 이를 저장한다.

두 번째, 해당 음에서 시작하여 진성구(modal register)로 대상 자 본인의 최고 음도에 이르기까지 /a/모음을 상행 스케일로 진 행하되, 필요시 다시 호흡을 하고 진행할 수 있도록 하면서 VRP 상에 이를 기록한다. 최고 음도에 이르러 본인이 멈추거나 음도 일탈(pitch break)이 관찰될 경우 중단한다. 사전에 1 회 모델링을 제공한다.

세 번째, 첫 번째 절차의 편안한 음도에서 시작하여 다시 최 저 음도에 이르기까지 /a/모음을 하행 스케일로 진행하도록 한 다. 최저 음도에 이르러 본인이 멈추거나 음도 일탈(pitch break) 이 관찰될 경우 중단한다. 사전에 1 회 모델링을 제공한다.

네 번째, 두 번째 절차의 최고 음도에 해당되는 건반을 클릭 하여 들려주고, 해당 음에서 시작하여 가성구(falsetto register)로 최고 음도에 이르기까지 /a/모음을 상행 스케일로 진행하도록 한다. 사전에 1 회 모델링을 제공한다.

\section{3. 분석}

Real-time EGG 프로그램에서는 전체 '가을' 문단 샘플의 평 균 기본주파수 $(\mathrm{Hz})$ 를 분석하여 $\mathrm{SFF}_{\mathrm{EGG}}$ 를 산정하였다. $\mathrm{VRP}$ 프로 그램에서는 $\mathrm{VRP}$ 와 $\mathrm{SRP}$ 플롯을 로드하여 최고 $\left(\mathrm{Max}_{\mathrm{VRP}}, \mathrm{Max}_{\mathrm{SRP}}\right)$ 및 최저 음도( $\left.\mathrm{Min}_{\mathrm{VRP}}, \mathrm{Min}_{\mathrm{SRP}}\right)$, 음역대(Range $\mathrm{VRP}_{\mathrm{VP}}$, Range $\left.\mathrm{SRP}_{\mathrm{SR}}\right)$, 반음 단위 음역대( $\left.\mathrm{Semi}_{\mathrm{VRP}}, \mathrm{Semi}_{\mathrm{SRP}}\right)$ 를 계산하였다. 또한 $\mathrm{VRP}$ 와 $\mathrm{SRP}$ 변수들에서 아래의 통계 방법을 통해 각각의 $\mathrm{ESFF}$ 를 계산하였 다 $\left(\mathrm{ESFF}_{\mathrm{VRP}}, \mathrm{ESFF}_{\mathrm{SRP}}\right)$. 마지막으로 $\mathrm{VRP}$ 와 $\mathrm{SRP}$ 에서 $\mathrm{ESFF}$ 와 $\mathrm{SFF}$ 간 차이의 절대값 $\left(\mathrm{DSFF}_{\mathrm{VRP}}, \mathrm{DSFF}_{\mathrm{SRP}}\right)$ 과 두 $\mathrm{DSFF}$ 의 합 $\left(\mathrm{DSFF}_{\mathrm{SUM}}\right)$ 을 계산하였다.

\section{4. 통계방법}

성별집단 간 측정치의 차이를 알아보기 위해 독립표본 $t$-검정 (independent $t$-test)을 시행하였다. VRP와 SRP를 통해 측정된 음 역대 관련 변수들(최고 및 최저음도, 음역대와 반음단위 음역 대)과 연령, 성별이 $\mathrm{EGG}$ 를 통해 측정된 $\mathrm{SFF}$ 를 예측할 수 있는지 알아보기 위해 단계적 다중회귀분석(stepwise regression analysis) 을 시행하였다. 통계 프로그램으로는 IBM SPSS statistics 25.0 (IBM-SPSS Inc., Armonk, NY, USA)를 사용하였고, 유의수준은 .05로 설정하였다.

\section{3. 연구 결과}

\section{1. 성별에 따른 과제별 측정치}

성별에 따른 $\mathrm{EGG}, \mathrm{VRP}, \mathrm{SRP}$ 의 측정치의 비교 결과가 표 1에 제시되어 있다. $\mathrm{SFF}_{\mathrm{EGG}}, \mathrm{Max}_{\mathrm{VRP}}$, Min ${ }_{\mathrm{VRP}}$, Range $\mathrm{VRP}_{\mathrm{VR}}, \mathrm{Max}_{\mathrm{SRP}}, \mathrm{Min}_{\mathrm{SRP}}$, RangesRP의 경우 남성보다 여성의 측정치가 높았다. 반면 SemivRP 의 경우 남성이 여성보다 더 높은 측정치를 보였으며, SemisRP는 성별 집단 간 차이를 보이지 않았다. 
표 1. 성별 집단 간 $\mathrm{EGG}, \mathrm{VRP}, \mathrm{SRP}$ 측정치의 비교

Table 1. Comparison of the EGG, VRP, and SRP measures between gender groups

\begin{tabular}{l|r|r|r|r|r}
\hline \multirow{2}{*}{ Parameters } & \multicolumn{2}{|c|}{ Male $(\mathrm{N}=30)$} & \multicolumn{2}{c|}{ Female $(\mathrm{N}=55)$} & \multirow{2}{*}{$t$-value } \\
\cline { 2 - 5 } & \multicolumn{1}{c|}{$M$} & \multicolumn{1}{c}{$S D$} & \multicolumn{1}{c}{$M$} & \multicolumn{1}{c}{$S D$} & \\
\hline $\mathrm{SFF}_{\mathrm{EGG}}(\mathrm{Hz})$ & 107.429 & 11.211 & 192.555 & 15.383 & $-26.663^{* * *}$ \\
\hline $\mathrm{Max}_{\mathrm{VRP}}(\mathrm{Hz})$ & 589.254 & 153.920 & 755.536 & 182.100 & $-4.240^{* * *}$ \\
\hline $\mathrm{Min}_{\mathrm{VRP}}(\mathrm{Hz})$ & 84.342 & 10.889 & 147.002 & 18.127 & $-19.888^{* * *}$ \\
\hline Range $_{\mathrm{VRP}}(\mathrm{Hz})$ & 505.547 & 154.851 & 608.384 & 185.237 & $-2.586^{*}$ \\
\hline Semi $_{\mathrm{VRP}}$ & 33.233 & 5.740 & 27.909 & 5.250 & $4.323^{* * *}$ \\
\hline Max $_{\mathrm{SRP}}(\mathrm{Hz})$ & 136.127 & 19.563 & 250.378 & 23.138 & $-22.927^{* * *}$ \\
\hline Min $_{\mathrm{SRP}}(\mathrm{Hz})$ & 89.879 & 11.628 & 166.001 & 16.715 & $-22.162^{* * *}$ \\
\hline Range $_{\mathrm{SRP}}(\mathrm{Hz})$ & 46.248 & 16.421 & 84.378 & 21.265 & $-9.191^{* * *}$ \\
\hline Semin $_{\mathrm{SRP}}$ & 7.167 & 2.036 & 7.127 & 1.733 & 0.094 \\
\hline
\end{tabular}

$\mathrm{SFF}_{\mathrm{EGG}}$, speaking fundamental frequency measured by electroglottography; VRP, voice range profile; SRP, speech range profile; Max, maximum pitch in $\mathrm{Hz}$; Min, minimum pitch in $\mathrm{Hz}$; Range, pitch range in $\mathrm{Hz}$; Semi, pitch range in semitones; ${ }^{*} p<.05,{ }^{* * *} p<.001$

\section{2. 과제별 $\mathrm{SFF}$ 의 예측 모형}

$\mathrm{SFF}$ 에 대한 VRP와 SRP의 예측 모형은 모두 유의하였으며 $(p<.001)$, 모형의 요약 결과가 표 2와 표 3에 제시되어 있다. SFF 의 예측 변인은 $\mathrm{VRP}$ 에서는 최저음도 $(\mathrm{Hz})$, 음도범위 $(\mathrm{Hz})$, 성별, 연령(adjusted $R^{2}=.931$ )이었으며, SRP에서는 반음 단위 음역대와 최고음도 $(\mathrm{Hz})$ (adjusted $\left.R^{2}=.963\right)$ 였다. 두 모형 모두에서 다중공 선성은 문제시되지 않았다.

표 2. VRP 측정치를 이용하여 $\mathrm{SFF}$ 를 예측하는 회귀 모형 요약 Table 2. Summary of the regression models predicting the SFF with VRP and SRP measures

\begin{tabular}{c|c|c|c|c|c|c}
\hline $\begin{array}{c}\text { Predictive } \\
\text { factors }\end{array}$ & $\begin{array}{c}\text { Adjusted } \\
R^{2}\end{array}$ & $F$ change & $d f$ & $\beta$ & $\begin{array}{c}\text { Standardized } \\
\text { beta }\end{array}$ & $p$-value \\
\hline Gender & .894 & 710.913 & 1,83 & 57.116 & .635 & $<.001^{* * *}$ \\
\hline $\begin{array}{c}\text { Min }_{\mathrm{VRP}} \\
(\mathrm{Hz})\end{array}$ & .918 & 25.461 & 1,82 & 0.447 & .352 & $<.001^{* * *}$ \\
\hline Age & .928 & 12.202 & 1,81 & -0.308 & -.082 & $.001^{* *}$ \\
\hline $\begin{array}{c}\text { Range } \\
(\mathrm{Hz})\end{array}$ & .931 & 4.153 & 1,80 & 0.016 & .066 & $.045^{*}$ \\
\hline
\end{tabular}

VRP, voice range profile; Min, minimum pitch in Hz; Range, pitch range in $\mathrm{Hz} ;{ }^{*} p<.05,{ }^{* *} p<.01,{ }^{* * *} p<.001$.

표 3. SRP 측정치를 이용하여 $\mathrm{SFF}$ 를 예측하는 회귀 모형 요약 Table 3. Summary of the regression models predicting the SFF with VRP and SRP measures

\begin{tabular}{c|c|r|c|c|c|c}
\hline $\begin{array}{c}\text { Predictive } \\
\text { factors }\end{array}$ & $\begin{array}{c}\text { Adjusted } \\
R^{2}\end{array}$ & $F$ change & $d f$ & $\beta$ & $\begin{array}{c}\text { Standardized } \\
\text { beta }\end{array}$ & $p$-value \\
\hline $\begin{array}{c}\text { Max }_{\text {SRP }} \\
(\mathrm{Hz})\end{array}$ & .943 & $1,395.508$ & 1,83 & 0.728 & .995 & $<.001^{* * *}$ \\
\hline Semi $_{\text {SRP }}$ & .963 & 44.075 & 1,82 & -3.353 & -.142 & $<.001^{* * *}$ \\
\hline
\end{tabular}

SRP, speech range profile; Max, maximum pitch in $\mathrm{Hz}$; Semi, pitch range in semitones; ${ }^{* * *} p<.001$.

따라서 위의 모형에 따라 아래와 같은 회귀식을 이용하여 $\mathrm{ESFF}_{\mathrm{VRP}}$ 와 $\mathrm{ESFF}_{\mathrm{SRP}}$ 를 산정하였다.
$E S F F_{V R P}$

$=71.779+(57.116 \times$ Gender $)+\left(0.447 \times\right.$ Min $\left._{V R P}\right)$

$-(0.308 \times$ Age $)+\left(0.016 \times\right.$ Range $\left._{V R P}\right)$

$E S F F_{S R P}$

$=33.446+\left(0.728 \times \operatorname{Max}_{\text {SRP }}\right)-\left(3.353 \times \operatorname{Semi}_{\text {SRP }}\right)$

$\mathrm{SFF}_{\mathrm{EGG}}$ 와 VRP(Pearson's $r=.873, p<.001$, 그림 1), $\mathrm{SRP}$ (Pearson's $r=.932, p<.001$, 그림 2)를 통해 예측된 $\mathrm{ESFF}$ 와 사이에는 공통적 으로 강한 양의 상관관계가 있었다.

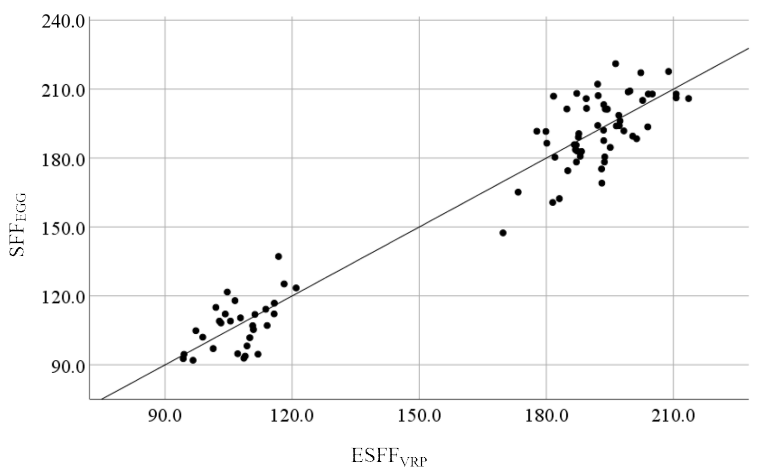

$\mathrm{SFF}_{\mathrm{EGG}}$, speaking fundamental frequency measured by electroglottography; VRP, voice range profile; ESFF, estimated speaking fundamental frequency.

그림 1. $\mathrm{ESFF}_{\mathrm{VRP}}$ 와 $\mathrm{SFF}_{\mathrm{EGG}}$ 의 산점도와 회귀 적합선

Figure 1. A scatterplot and its regression line for $\mathrm{ESFF}_{\mathrm{VRP}}$ and $\mathrm{SFF}_{\mathrm{EGC}}$

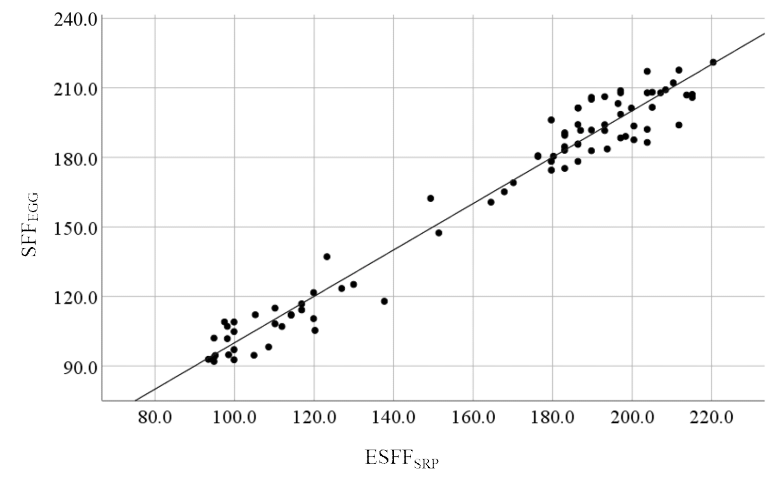

$\mathrm{SFF}_{\mathrm{EGG}}$, speaking fundamental frequency measured by electroglottography; VRP, voice range profile; ESFF, estimated speaking fundamental frequency.

그림 2. $\mathrm{ESFF}_{\mathrm{SRP}}$ 와 $\mathrm{SFF}_{\mathrm{EGG}}$ 의 산점도와 회귀 적합선

Figure 2. A scatterplot and its regression line for $\mathrm{ESFF}_{\mathrm{SRP}}$ and $\mathrm{SFF}_{\mathrm{EGG}}$

\section{3. 과제별 $\mathrm{SFF}$ 와 $\mathrm{ESFF}$ 의 차이}

위의 과제별 $\mathrm{SFF}$ 예측 모형에 따라 산정된 $\mathrm{ESFF}_{\mathrm{VRP}}$ 와 $\mathrm{ESFF}_{\mathrm{SRP}}$ 그리고 이들과 $\mathrm{SFF}_{\mathrm{EGG}}$ 간의 차이를 나타낸 $\mathrm{DSFF}_{\mathrm{VRP}}$ 와 $\mathrm{DSFF}_{\mathrm{SRP}}$ 의, 그리고 이들의 합계인 $\mathrm{DSFF}_{\mathrm{SuM}}$ 의 성별 집단 간 비교 결과가 표 4에 제시되어 있다. ESFF는 과제와 무관하게 여성이 남성 보다 높았으나, $\mathrm{DSFF}_{\mathrm{VRP}}$ 와 $\mathrm{DSFF}_{\mathrm{SRP}}, \mathrm{DSFF}_{\mathrm{SUM}}$ 의 성별 차이는 없 었다. 
표 4. 성별 집단 간 $\mathrm{ESFF}$ 와 $\mathrm{DSFF}$ 의 비교 Table 4. Comparison of the ESFF and DSFF between gender groups

\begin{tabular}{l|r|r|r|r|l}
\hline \multirow{2}{*}{ Parameters } & \multicolumn{2}{|c|}{ Male $(\mathrm{N}=30)$} & \multicolumn{2}{c|}{ Female $(\mathrm{N}=55)$} & \multirow{2}{*}{ t-value } \\
\cline { 2 - 5 } & \multicolumn{1}{c|}{$M$} & \multicolumn{1}{c|}{$S D$} & \multicolumn{1}{c}{$M$} & \multicolumn{1}{c}{$S D$} & \\
\hline $\operatorname{ESFF}_{\mathrm{VRP}}(\mathrm{Hz})$ & 107.456 & 7.049 & 192.568 & 9.260 & $-43.847^{* * *}$ \\
\hline $\operatorname{ESFF}_{\mathrm{SRP}}(\mathrm{Hz})$ & 108.517 & 12.050 & 191.824 & 15.061 & $-26.063^{* * *}$ \\
\hline $\operatorname{DSFF}_{\mathrm{VRP}}(\mathrm{Hz})$ & 7.321 & 5.666 & 9.683 & 7.016 & -1.582 \\
\hline $\operatorname{DSFF}_{\mathrm{SRP}}(\mathrm{Hz})$ & 5.945 & 4.799 & 6.767 & 5.252 & -0.711 \\
\hline $\operatorname{DSFF}_{\mathrm{SUM}}(\mathrm{Hz})$ & 13.266 & 8.245 & 16.450 & 8.086 & -1.723 \\
\hline $\operatorname{ESFF}$
\end{tabular}

ESFF, estimated speaking fundamental frequency; DSFF, differences between the ESFF and the SFF measured by electroglottography of a passage reading task; VRP, voice range profile; SRP, speech range profile; ${ }^{*} p<.05,{ }^{* * *} p<.001$.

\section{4. 논의 및 결론}

본 연구에서는 한국인 정상 성인에서 $\mathrm{VRP}$ 및 $\mathrm{SRP}$ 의 측정 변 수들을 이용하여 문단 읽기 시 $\mathrm{EGG}$ 를 통해 측정한 평균 $\mathrm{SFF}$ 를 예측할 수 있는지 알아보고자 하였다. 또한 $\mathrm{ESFF}$ 와 실제 SFF 간 차이를 나타내는 DSFF에 있어 성별 차이가 있는지 알아보고자 하였다. 연구 결과, SFF를 예측할 수 있는 두 가지의 회귀 모형 이 제시되었으며, DSFF의 성별 차이가 없음을 확인하였다.

먼저 $\mathrm{EFF}_{\mathrm{EGG}}, \mathrm{Max}_{\mathrm{VRP}}$, Min VRP , Range $\mathrm{VRP}_{\mathrm{VP}}, \mathrm{Max}_{\mathrm{SRP}}$, Min SRP , Range $\mathrm{SRP}_{\mathrm{SP}}$ 의 경우 남성보다 여성이 높았는데, 이는 선행연구와도 일맥상 통하며 성별에 따른 음역대를 고려하면 놀랍지 않은 결과이다 (Jung, 2018; Kim, 2010). 반면 Semi $\mathrm{VRP}_{\mathrm{N}}$ 의 경우 남성이 여성보다 더 높은 측정치를 보였으며, SemisRP는 성별 집단 간 차이가 없 었다. 이는 언뜻 보면 주파수 $(\mathrm{Hz})$ 를 기준으로 살펴 본 앞의 비교 결과에 비추어 볼 때 모순된 결과인 것처럼 보일 수 있으나, 같 은 반음 차이라고 하더라도 고음역대에 이르면 주파수의 차이 가 커진다는 점에 의해 일부 설명될 수 있다. 즉 VRP의 매뉴얼 (부록 $\mathrm{E}$ )을 살펴보면 각 옥타브의 레이블링은 $\mathrm{A}$ 에서 $\mathrm{G} \#$ 까지 이 루어지고 있으며, 기준점으로 볼 수 있는 $\mathrm{A} 1, \mathrm{~A} 2, \mathrm{~A} 3, \mathrm{~A} 4$ 에 해당 되는 주파수 값은 각각 $55,110,220,440 \mathrm{~Hz}$ 등이며, 이는 각 주파 수에 해당되는 반음 값을 계산할 때 로그함수를 취하게 되기 때 문이다. 따라서 얼핏 모순되어 보이는 이러한 결과는 사실 서로 부합하는 결과라 할 수 있다.

다른 한편으로 모음을 이용하여 검사한 음역대에 있어 남성 이 여성보다 실질적인 반음단위의 범위가 더 넓다는 것은 본 연 구에서 가성을 이용한 발성을 포함한 것도 영향을 끼쳤을 것으 로 보인다. 또한 그럼에도 불구하고 ‘우리나라의 가을은 참으로 아름답다' 문장 산출 시 반음 단위의 음역대는 남녀 각각 평균 7.167 개와 7.127개의 반음으로 성별 간 차이가 없음을 시사하였 다. 해당 문장을 좀 더 자세히 살펴보면, ‘참으로'라고 하는 부사 어에서 강조를 하는 의미로 음도가 상승하고, 평서문이므로 문 장 말미의 '아름답다'라고 하는 용언에서 음도가 하강하는 패턴 을 보였으며, 이러한 패턴이 성별과 무관하게 공히 나타난 것으 로 보인다. 다만 이는 본 연구의 과제가 감탄문, 명령문, 의문문 등 다른 문장 유형에서의 음역대를 살펴보지는 못했다는 한계 를 드러내는 것이기도 하다.
다음으로 SFF에 대한 VRP와 SRP의 예측 모형은 각각 예측 변인이 달랐다. 구체적으로는 VRP에서는 최저음도, 음도범위, 성별, 연령이었으며, SRP에서는 반음 단위 음역대와 최고음도 였다. 이중 VRP에서는 최저음도가, SRP에서는 최고음도가 예 측변인이었다는 점은 흥미롭다. 이는 부분적으로는 개인에 따 라 VRP에서 최저음도보다는 최고음도가 다양하게 나타날 수 있다는 것과 무관치 않아 보인다. 한편 SRP의 최고음도는 반음 단위로 살펴볼 필요가 있는데, 남성에서 평균 $136.127 \mathrm{~Hz}(\mathrm{C \# 3)}$, 여성에서 $250.378 \mathrm{~Hz}(\mathrm{~B} 3)$ 였으며, 남성과 여성의 $\mathrm{SFF}$ (각각 대략 $\mathrm{A} 2$ 와 $\mathrm{G} 3$ )와 4개 정도의 반음 차이를 나타낸 것으로 설명이 가능 하다.

이와 더불어 VRP의 측정치들을 이용하여 $\mathrm{SFF}$ 를 예측할 때에 는 음역대와 관련된 변수 이외에도 연령과 성별 정보가 중요하 였던 것을 확인하였다. 구체적으로 살펴보면, 다른 요인이 통제 되었을 때 ESFF는 여성이 남성에 비해 $57.116 \mathrm{~Hz}$ 높았으며, 연 령이 1 세 증가함에 따라 $0.308 \mathrm{~Hz}$ 감소하였다. 이러한 점을 고려 하면, 추후 VRP를 이용한 연구에서 연령과 성별이라는 인구학 적 정보를 중요하게 고려하여 통제하여야 함을 유추할 수 있다.

모형 자체의 예측력을 나타내는 adjusted $R^{2}$ 는 VRP와 SRP에 서 각각 .931과 .963으로 매우 높았으며, $\mathrm{SFF}_{\mathrm{EGG}}$ 와 VRP(Pearson's $r=.873$ ), SRP(Pearson's $r=.932$, 를 통해 예측된 ESFF와 사이에 공 통적으로 강한 양의 상관관계가 있었다는 점도 이러한 점을 뒷받침한다. 구체적으로 측정치와 추정치를 살펴보면, 남성의 경우 $\mathrm{SFF}_{\mathrm{EGG}}$ 는 $107.429 \pm 11.211 \mathrm{~Hz}, \mathrm{ESFF}_{\mathrm{VRP}}$ 는 $107.456 \pm 7.049 \mathrm{~Hz}$, $\mathrm{ESFF}_{\mathrm{SRP}}$ 는 $108.517 \pm 12.050 \mathrm{~Hz}$ 이었으며, 여성의 경우 $\mathrm{SFF}_{\mathrm{EGG}}$ 는 $192.555 \pm 15.383 \mathrm{~Hz}, \mathrm{ESFF}_{\mathrm{VRP}}$ 는 $192.568 \pm 9.260 \mathrm{~Hz}, \mathrm{ESFF}_{\mathrm{SRP}}$ 는 $191.824 \pm 15.061 \mathrm{~Hz}$ 로 성별에 무관하게 매우 유사한 측정치들을 보임을 알 수 있다. 다만 $\mathrm{EGG}$ 를 이용한 $\mathrm{Kim}(2010)$ 의 국내 선행 연구에서 나타난 성별에 따른 SFF 측정치는 남성 $119.02 \pm 15.96$ $\mathrm{Hz}$, 여성 $226.17 \pm 19.37 \mathrm{~Hz}$ 로 여성의 SFF가 본 연구에 비해 다소 높은 경향이 있었고, 오히려 서론에서 언급한 Berg et al.(2017)의 선행연구의 결과의 범위와 다소 유사하였다. 이는 해당 국내 연 구의 여성의 연령이 평균 $25.75 \pm 4.44$ 세로 본 연구의 $38.22 \pm 10.40$ 세에 비해 낮았으며, 부분적으로는 연구에 사용된 기기(CSL vs. Lx Speech Studio)의 차이에도 일부 기인했을 것으로 보인다. 다 만 과제와 무관하게 여성의 ESFF가 남성보다 높았던 결과는 해 당 선행연구와도 일치하였다.

마지막으로 DSFF의 경우 유의한 성별 차이가 없었다. 이는 DSFF가 음도 범위의 이상을 나타내는 환자군의 특징을 DSFF로 살펴보고자 할 때 성별과 무관하게 공히 적용될 수 있는 가능성 을 제시하였다고 볼 수 있다. 다만 앞서 언급하였듯이 성대의 접 촉이 거의 이루어지지 않는 심한 중증도의 성대마비 환자와 같 은 경우 $\mathrm{EGG}$ 를 통해 신뢰성 있게 측정할 수 없는 경우가 있을 수 있는 만큼, 단순히 환자군과 정상군을 구분 짓는 후속연구 뿐 만 아니라 특정 질환군에 대한 보다 상세한 후속연구가 반드시 필요할 것으로 여겨진다.

결론적으로 본 연구에서는 정상 성인에서 VRP와 SRP를 통해 문단 읽기 시 SFF를 예측할 수 있는 모형을 제시하였다는 데 연 
구의 의의가 있다. 또한 정상 성인에서 모음을 이용한 발성 시, 그리고 간단한 평서문 문장 산출 시 VRP 프로그램을 통해 확인 할 수 있는 음역대 관련 정상 기준치를 일부 제시하였다는 의의 도 있다. 다만 이는 어디까지나 음도 범위에 국한된 것이었으며, 음성의 강도에 대한 부분은 연구에 포함하지 못하였다는 한계 가 명확하다. 또한 남녀 성비가 달랐으며, 문장과 문단 읽기 모 두 우리가 일상생활에서 산출하는 음성의 음도 및 강도의 범위 를 오롯이 반영한다고 보기에는 어려운 측면이 있을 수 있다는 한계도 있다. 마지막으로 이러한 음도 예측 모형, 그리고 $\mathrm{ESFF}$ 와 실제 SFF와의 차이를 나타내는 DSFF 변수들이 갖는 임상적 의의에 대해서는 아직 살펴보지 못하였다.

$\mathrm{VRP}$ 나 SRP 관련 측정치 자체가 음성장애 선별에 기여할 수 있는 가능성이 이미 보고되어 온 만큼(Ma et al., 2007), 본 연구 에서 제시한 이러한 변수들이 갖는 의의를 확장하고자 한다면 다양한 직업군에서의 차이를 탐색하거나, $\mathrm{SFF}$ 의 이상을 보일 수 있는 음성장애 환자에서 후속 연구를 통하여 진단력이나 특 정 중재 이후의 반응도 측면에서 임상적 시사점을 탐색할 필요 가 있을 것으로 여겨진다. 아울러 보다 궁극적으로는 음성장애 환자에서 다양한 말 또는 음성 산출의 범위를 종합적으로 측정 및 반영할 수 있는 보다 포괄적인 형태의 프로토콜이 제시될 필 요성이 크다고 판단된다.

\section{감사의 글}

본 연구는 2018년 대한민국 교육부와 한국연구재단의 지원 을 받아 수행된 연구임(NRF-2018S1A5A2A03032902).

\section{References}

Berg, M., Fuchs, M., Wirkner, K., Loeffler, M., Engel, C., \& Berger T. (2017). The speaking voice in the general population: Normative data and associations to sociodemographic and lifestyle factors. Journal of Voice, 31(2), 257.e13-257.e24.

D'Alatri, L., \& Marchese M. R. (2014). The speech range profile (SRP): An easy and useful tool to assess vocal limits. Acta Otorhinolaryngologica Italica, 34(4), 253-258.

Faul, F., Erdfelder, E., Buchner, A., \& Lang, A. G. (2009). Statistical power analyses using G*Power 3.1: Tests for correlation and regression analyses. Behavior Research Methods, 41(4), 11491160.

Herbst, C. T., \& Dunn, J. C. (2019). Fundamental frequency estimation of low-quality electroglottographic signals. Journal of Voice, 33(4), 401-411.

Hirano, M. (1981). Clinical examination of voice. New York, NY: Springer.

Jung, W. J. (2018). Development and validation of a simplified voice range profile (VRP) measurement for patients with voice disorder (Master's thesis). Daegu Catholic University, Korea.
KayPENTAX (2009). Voice Range Profile (VRP) Model 4326, Software Instruction Manual. Montvale, NJ: KayPENTAX .

Kim, H. (2012). Neulologic speech-language disorders. Seoul: Sigma Press.

Kim, J. O. (2010). The analysis of eletroglottographic measures of vowel and sentence in Korean healthy adults. Phonetics and Speech Sciences, 2(4), 223-228.

Lee, S. J., Choi, H. S., Kim, H. H., Byeon, H. K., Lim, S. E., \& Yang, M. K. (2016). Korean version of the voice activity and participation profile (K-VAPP): A validation study. Communication Sciences \& Disorders, 21(4), 695-708.

Lee, S. J., Choi, H. S., Lim, J. Y., \& Lee, K. Y. (2018). The effect of the Modified Voiced Lip Trill (MVoLT) training on vocal changes of musical theater students. Phonetics and Speech Sciences, 10(4), 135-146.

Lee, S. J., Lim, S. E., \& Choi, H. S. (2017). Responsiveness of the Korean version of the voice activity and participation profile (K-VAPP) after surgical intervention. Communication Sciences \& Disorders, 22(2), 379-390.

Ma, E. P. M., \& Lam, N. L. N. (2015). Speech task effects on acoustic measure of fundamental frequency in Cantonese-speaking children. International Journal of Pediatric Otorhinolaryngology, 79(12), 2260-2264.

Ma, E. P., \& Yiu, E. M. (2011). Handbook of voice assessments. San Diego, CA: Plural Pub.

Ma, E., Robertson, J., Radford, C., Vagne, S., El-Halabi, R., \& Yiu, E. (2007). Reliability of speaking and maximum voice range measures in screening for dysphonia. Journal of Voice, 21(4), 397-406.

Sataloff, R. T. (2005). Clinical assessment of voice. San Diego, CA: Plural Pub.

- 이승진 (Seung Jin Lee) 교신저자

연세대학교 의과대학 이비인후과학교실 연구조교수 및 강남 세브란스병원 이비인후과 후두음성언어의학연구소 연구원 서울시 강남구 언주로 211

Tel: 02-2019-2589 Fax: 02-3463-4750

Email: slplee@yuhs.ac

관심분야: 음성장애, 음성언어의학, 신경말언어장애

\section{- 김재옥 (Jaeock Kim)}

강남대학교 교육대학원 언어치료교육전공 부교수 용인시 기흥구 강남로 40 강남대학교 샬롬관 1013 호

Tel: 031-280-3221 Fax: 031-275-4244

Email: jaeock@gmail.com

관심분야: 말장애, 음성장애, 음성의학 


\title{
정상 성인에서 음성 및 말소리 범위 프로파일을 이용한 발화 기본주파수 예측*
}

\author{
이 승 진 ${ }^{1} \cdot{\text { 김 } \text { 재 }^{2}{ }^{2}}^{2}$
}

${ }^{1}$ 연세대학교 의과대학 이비인후과학교실 및 강남세브란스병원 이비인후과 후두음성언어의학연구소,

2강남대학교 교육대학원 언어치료교육전공

\section{국문초록}

본 연구에서는 한국인 정상 성인에서 음성(VRP) 및 말소리 범위 프로파일(SRP)을 이용하여 문단 읽기 시 전기성문 파형검사(EGG)를 이용하여 측정한 평균 발화 기본주파수 $(\mathrm{SFF})$ 를 예측할 수 있는지 알아보고자 하였다. 또한 추정 된 기본주파수(ESFF)와 실제 SFF 간 차이(DSFF)에 있어 성별 차이가 있는지 알아보고자 하였다. 연구대상은 정상 음성을 가진 한국어 모국어 화자 85 명이었다. 각 대상자는 /al 발성으로 전체 음역대를 측정하는 VRP 과제, '가을' 문단의 첫 번째 문장을 읽어 말소리 산출 시 음역대를 측정하는 SRP 과제, 전체 문단을 읽어 SFF를 측정하는 문단 읽기 과제를 수행하였다. VRP와 SRP를 통해 측정된 음역 대 관련 변수들와 연령, 성별이 $\mathrm{EGG}$ 를 통해 측정된 SFF를 예측할 수 있는지 알아보기 위해 단계적 다중회귀분석을 시행하였고, 예측된 ESFF와 SFF 간 차이의 절대값(DSFF) 과 그 합계를 구하였다. 연구 결과, $\mathrm{SFF}$ 의 예측변인은 VRP에서는 최저음도, 음도범위, 성별, 연령(adjusted $R^{2}=.931$ ) 이었으며, SRP에서는 반음 단위 음역대와 최고음도(adjusted $R^{2}=.963$ )였다. VRP와 SRP를 통해 예측된 두 가지 $\mathrm{ESFF}$ 와 실제 SFF 사이에는 강한 양의 상관관계가 있었다. VRP와 SRP를 이용한 DSFF와 그 합계에 있어 성별 차이 는 없었다. 결론적으로 VRP와 SRP를 통해 문단 읽기 시 SFF를 예측할 수 있었으며, SFF의 이상을 보일 수 있는 음 성장애 환자에서 후속 연구를 통하여 임상적 시사점을 탐색할 필요가 있을 것으로 여겨진다.

핵심어: 음성 범위 프로파일, 말소리 범위 프로파일, 발화 기본주파수

\section{참고문헌}

김재옥 (2010). 한국 정상 성인의 모음과 문단 산출시 전기성문파 형 측정. 말소리와 음성과학, 2(4), 223-228.

김향희 (2012). 신경언어장애. 서울: 시그마프레스.

이승진, 최홍식, 김향희, 변형권, 임성은, 양민교 (2016). 음성 활 동 및 참여 프로파일-한국판(K-VAPP): 타당성 검증 연구. 언 어청각장애연구, 21(4), 695-708.

이승진, 임성은, 최홍식 (2017). 수술적 중재 후 음성 활동 및 참여 프로파일-한국판(K-VAPP)의 반응도 연구. 언어청각장애연 구, 22(2), 379-390.

이승진, 최홍식, 임재열, 이광용 (2018). 응용 입술 트릴 훈련이 뮤 지컬 전공 학생의 음성 변화에 미치는 효과. 말소리와 음성과 학, 10(4), 135-146.

정원정 (2018). 음성장애 환자를 위한 축약된 음성범위프로파일 (Voice Range Profile, VRP) 검사법 개발과 타당도. 대구가톨릭 대학교 석사학위논문.

\footnotetext{
* 본 연구는 2018년 대한민국 교육부와 한국연구재단의 지원을 받아 수행된 연구임(NRF-2018S1A5A2A03032902).
} 